\title{
Tactical offensive variables of penalty corner in World Cup men's hockey 2014
}

\author{
Samir Shaaban Abd El- Hamid Houta *
}

*Lecturer, Department of sportive games training, Faculty of physical education for men, Alexandria University

\section{Introduction and research problem:}

Rapid and successive Internationally developments in competitive sportive activities generally and in hockey particularly resulted in changing the game map and increasing the difficulty of the competition and win, which make it is necessary for the specialists in the field hockey to develop the scientific thought of aspects related to the game.

Karen Murtaugh (2000) stated that most of researches in field hockey were completed over 10 years ago; however the game has undergone significant changes since that time, so we need more studies to keep abreast of these developments. (13: 201)

Hassanein,M,S and Abdel- Moneim,H. (1997) refer to the enormous rapid development in all sportive activities particularly team games in skills and tactical, wherefore coaches must follow up everything that happens in fields, and then competitions have shown the importance of studying skills and tactically components more accurately, to identify minute characteristics, and use appropriate research methods in order to reach the ideal athletic performance. (8: 476)

Muhammad,K,H.(2000) stated that determination of motor and tactical performance characteristics of players during competition help to detect factors causing win and loss. (23: 3 )

The researcher believes that line between win and lose in team sports such as field hockey is scoring and score the heights number of goals, as the progress in the level of physical, skill and tactical abilities of players ultimately aimed for access to the scoring position from which he can score a goal.

In field hockey, there are many positions within the match ends shooting at goal, including open play score, counter attack and fixed hits scoring (penalty stroke - penalty corner -free hit - long corner), the most important of which is penalty corner. Scoping study conducted by researcher attachment (1) in the final, semifinal and matches of team's ranking from third to twelfth in World Cup men's hockey 2014, which was held in Netherlands, showed that number of goals scored was 35 goal, 15 of them from the penalty corner which represent $42.85 \%$, that confirms its extreme importance in scoring goals.

Shirazi,J (1994), Ward, C (1998) Laird, P., and Sutherland, P (2003), Hockey Rules Boord (2004), Mitchell-Taverner (2005), Mari, H, M and Ali,M (2006), Kerr,R and Ness,K (2006) Anders,E (2008), de Subijana et al (2011), Hussain et al (2012), Viswanath and Kalidasan (2014) agreed that, penalty corner considered one of the most important position in goal 
scoring. Many teams loss important final matches as a result of complacency in penalty corner performance. (28: 59) (33:45) $(15: 19,26)$ (9:36) (21:133) $(18: 343)(14: 47)(2: 202)(4: 590)(11: 187)(32: 35)$

Don Vinson et al (2013) showed that relatively little field hockey research has focused on coaches and players tactical and strategic decision making in relation to performance. Recent performance analysis research in field hockey has advanced the understanding of movement patterns at the elite level (MacLeod et al 2009) (17). Other recent research has investigated the impact of the fundamental rule changes applied to field hockey in recent years concerning the enabling of players to 'self-pass' from free hits (Tromp and Holmes (2011)(30). A small number of articles have focused on the actions surrounding penalty corners, despite its importance in goal scoring, so we need more studies on it. (7:887).

Through reference survey for Studies and Researches, researcher find out six axes through which penalty corner was studied, first trend is the relationship between penalty corner and matches results, Hosni, I. (1974)(10), Laird, $\mathbf{P}$ and Sutherland, $\mathbf{P}$ (2003)(15).Second trend is to identify the effectiveness of penalty corner Salama,A (1993)(25).Third is to develop and improve penalty corner Kamal,A (2000)(12) de Subijana et al (2012)(5)Meulman ( 2012)(20), while the fourth trend mechanical analysis of drag flick skill in penalty corner Hussein,M and Abdel Salam,M (2006)(18) - Kerr.R and Ness,K (2006)(14) -de Subijana et al (2010)(6) -Viswanath and Kalidasan (2014)(31) -Bari et al (2014)(3) - Sathesh and Rajinikumar (2014)(27), The fifth is a comparison between long corner and penalty corner Amjad I. et al (2013)(1). Sixth Prediction of outcomes based on tactical decisions elite women's indoor field hockey Don Vinson et al (2013) (7), while Researcher cannot find any study in the tactical offensive performance of penalty corner

. That prompted the researcher to identify the tactical offensive variables of penalty corner in the World Cup men's hockey 2014 and which of them more effective in scoring goals; it's useful during players training on important and fixed positions to reach high sportive levels.

Aim of the research:

- Identify the most effective tactical offensive variables while performing the penalty corner in World Cup men's hockey 2014.

\section{Research questions:}

- What are the most effective tactical offensive variables while performing the penalty corner in World Cup men's hockey 2014?

\section{Research procedures:}

\section{Research Methodology:}

The researcher used the descriptive method in a survey manner because of its suitability for the nature and the purpose of the research.

\section{Research's fields:}

\section{A- Participants:}

The research sample selection purposively where was (38) matches for teams that participated in the World Cup of Hockey men 2014, which was held 
in Netherlands and they were twelve teams (Australia - Netherlands Argentina - England - Belgium - Germany - New Zealand - Spain - India South Korea - South Africa - Malaysia), the table below illustrates the ranking from the first to the second ten and the number of penalty corner for each team:

Table (1): Teams ranking and number of penalty corner in World Cup hockey men 2014.

\begin{tabular}{|c|c|c|}
\hline & Final ranking & No.Pinalty corner \\
\hline $\mathbf{1}$ & Australia & $\mathbf{3 5}$ \\
\hline $\mathbf{2}$ & Netherlands & $\mathbf{2 7}$ \\
\hline $\mathbf{3}$ & Argentina & $\mathbf{2 5}$ \\
\hline $\mathbf{4}$ & England & $\mathbf{2 2}$ \\
\hline $\mathbf{5}$ & Belgium & $\mathbf{3 7}$ \\
\hline $\mathbf{6}$ & Germany & $\mathbf{1 5}$ \\
\hline $\mathbf{7}$ & New Zealand & $\mathbf{2 2}$ \\
\hline $\mathbf{8}$ & Spain & $\mathbf{2 6}$ \\
\hline $\mathbf{9}$ & India & $\mathbf{1 7}$ \\
\hline $\mathbf{1 0}$ & South Korea & $\mathbf{8}$ \\
\hline $\mathbf{1 1}$ & South Africa & $\mathbf{1 8}$ \\
\hline $\mathbf{1 2}$ & Malaysia & $\mathbf{2 0}$ \\
\hline & Total & $\mathbf{2 7 2}$ \\
\hline
\end{tabular}

\section{B- The place of the study:}

Faculty of Physical Education for men, Alexandria University.

C- The time of the study:

- Scoping studies has been conducted from Monday 01/09/2014 to Sunday $09 / 14 / 2014$.

- Main study has been conducted from Sunday, 21/09/2014 to Monday 20/10/2014.

Means of data collection:

- DVD for matches.

- Lab top.

- Form for analysis of tactical offensive variables to perform penalty corner (designed by the researcher) attachment (2)

- Scoping studies:

1- First Scoping study:

Aim of study: hockey.

Identify tactical offensive variables to perform penalty corner in field

Procedures:

The researcher defined tactical offensive variables in penalty corner performance during his observation to elite level teams from Monday 09/01/2014 to Sunday 08/09/2014.

\section{Result of study:}

Researcher finds out many tactical variables used in penalty corner:

1. Passing the ball to the circle in the beginning of penalty corner through passing by drag, push.

2. Method of attacker's organization on the circle (one group - two groups). 
3. Methods of ball shooting after receiving it on the circle, which represents in:

- Direct shooting of the player receiving the ball using hit skill (Right of goal keeper- middle of the goal- left of goalkeeper).

- Shooting of player none receiving the ball using hit skill (Right of goal keeper- middle of the goal- left of goalkeeper).

- Shooting of player none receiving the ball using drag flick skill (Right of goal keeper- middle of the goal- left of goalkeeper).

- Passing the ball in the circle and shooting (Right of court- middle of goal- left of court).

\section{2- Second Scoping study:}

\section{Aim of study:}

Design an analysis form for tactical variables of penalty corner in field hockey.

\section{Procedures:}

The researcher has designed the form according to the results of the first scoping study, from Wednesday 11/09/2014 to Sunday 09/14/2014.

\section{Result of study:}

The researcher reached to final form. Attachment (2)

\section{- Main study:}

The researcher analyzed (272) penalty corners to twelve teams, which participated in the World Cup men's hockey (2014) in order to identify the most effective tactical offensive variables while performing the penalty corner in field hockey.

\section{Result and Discussion:}

1- Results of passing the ball to the circle in the beginning of penalty corner (passing ball by drag - push).

Figure (1): the skills used in passing the ball to the circle and goals resulted from it. $\quad \mathrm{N}=\mathbf{2 7 2}$

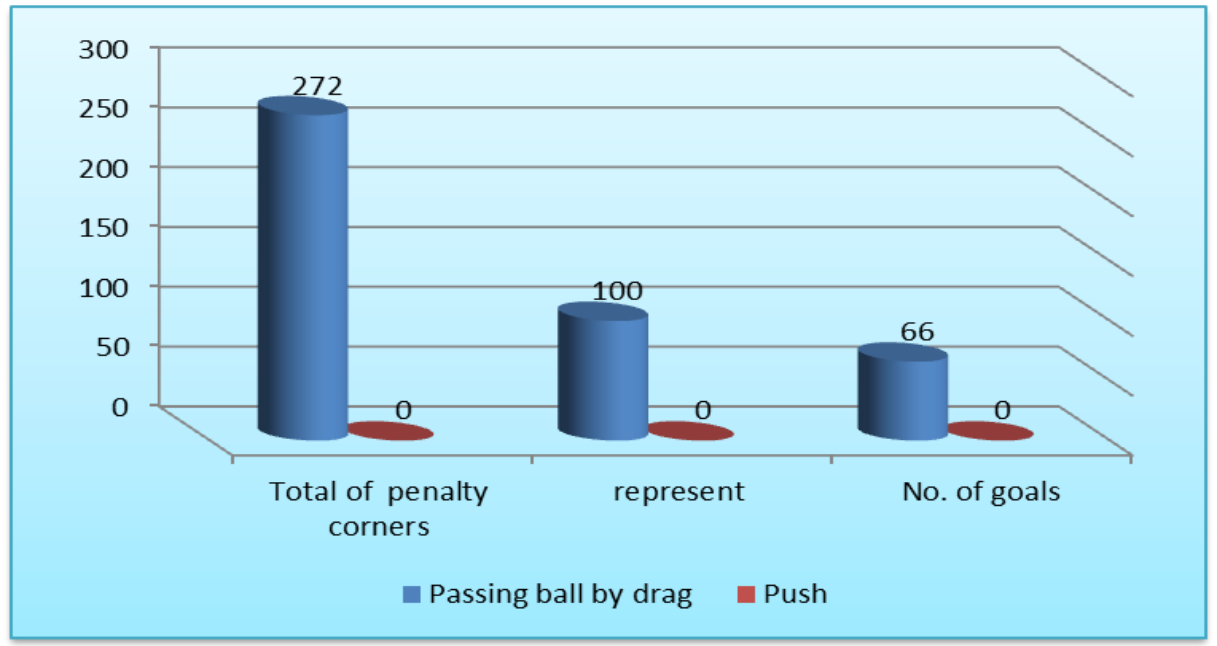

Figure (1) showed that the skill of passing the ball by drag is the most effective and widely used of all penalty corners for research sample teams during passing the ball to the circle ,that repeated (272) times which represent $(100 \%)$ of the total number ,and scored (66) goals. 
researcher explained that this skill has more speed and power than other skills, as there is a distance in which ball is dragged before passing, which give attackers a big chance of scoring goals before defenders obstruct them.

McLaughlin (1997) stated that, according to the rules of hockey, the ball placed on the back line near the goal while performing the penalty corner and one foot inside the circle, so the best skill used in this case is passing ball by drag because the left foot is inside the circle and away from the ball suitable distance give greater distance to drag the ball on the ground before they leave the stick increase its power and speed. (19:1)

Rebecca Kerr and Kevin Ness (2006) see that passing ball by drag has the most speed when it compared by other skills in field hockey, so it used heavily in ball entrance in penalty corner, so that coaches should pay special attention to maximize the distance between the left foot and the ball, that increase the drag distance of the ball then its speed. (14:49)

Marie,M,H, and Abdel Salam ,M.(2006) confirmed that passing ball by drag was extensively used in the first pass of entrance the ball in penalty corner, due to its speed ,strength and accuracy, and if this pass did not well performed, all the system often will be exposed to failure .(18:344)

2- Results of attackers organization on the circle during penalty corner:

Figure (2): Attackers organization on the circle during penalty corner and goals resulted from it. $\quad \mathrm{N}=272$

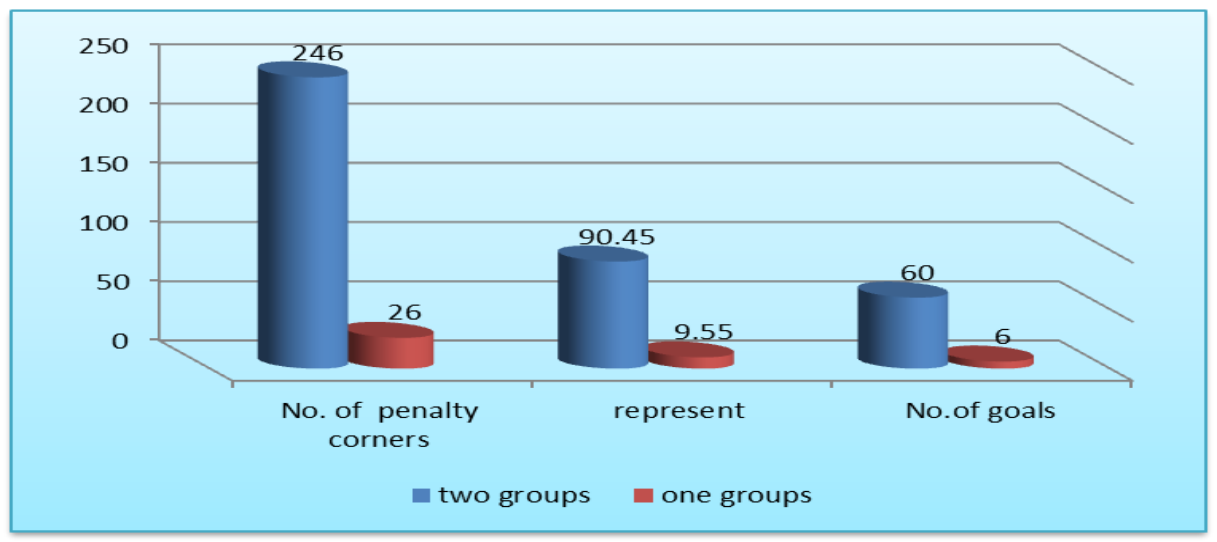

Figure (2) showed that Attackers organization on the circle during penalty corner as two groups is more effective and widely used than one group for research sample teams, that repeated (246) times which represent $(90.45 \%)$ of the total number , and scored (60) goals. While in one group, repeated only (26) and represent (9.55\%), and scored (6) goals.

Researcher explained that this method lead to defect for defenders and goalkeeper, make it is difficult to expect player who receive and shoot the ball, which increases the chance to score goals.

3- Results for methods of ball shooting after receiving it on the circle, during penalty corner for the research sample teams: 
-Direct shooting of the player receiving the ball using hit skill (Right of goal keeper- middle of the goal- left of goalkeeper).

Researcher found that it has been used only in few numbers during shooting on the goal and that repeated twice from the right of the goalkeeper, (5) times from the middle of the goalkeeper and did not score any goals.

-Shooting of player other than the one receiving the ball using hit skill (Right of goal keeper- middle of the goal- left of goalkeeper).

Researcher showed that it has been repeated twice only from the right of the goalkeeper and did not score any goals.

Researcher explained the little use of hit skill either through player receiving the ball or another player during shooting in penalty corner that recently drag flick skill heavily used due to its importance and effectiveness in scoring goals.

McLaughlin (1997), Pineiro et al (2007), Lees (2002), Sampedro et al (2008), Yusoff et al (2008) et al, de Subijana (2010) agreed that the drag flick is very Important when used in the shooting at goal during penalty corner in field hockey .(19)(24)(16)(26)(34)(6).

-Shooting of player other than the one receiving the ball using drag flick skill (Right of goal keeper- middle of the goal- left of goalkeeper).

Figure (3): Shooting of the player none receiving the ball using drag flick skill in penalty corner.

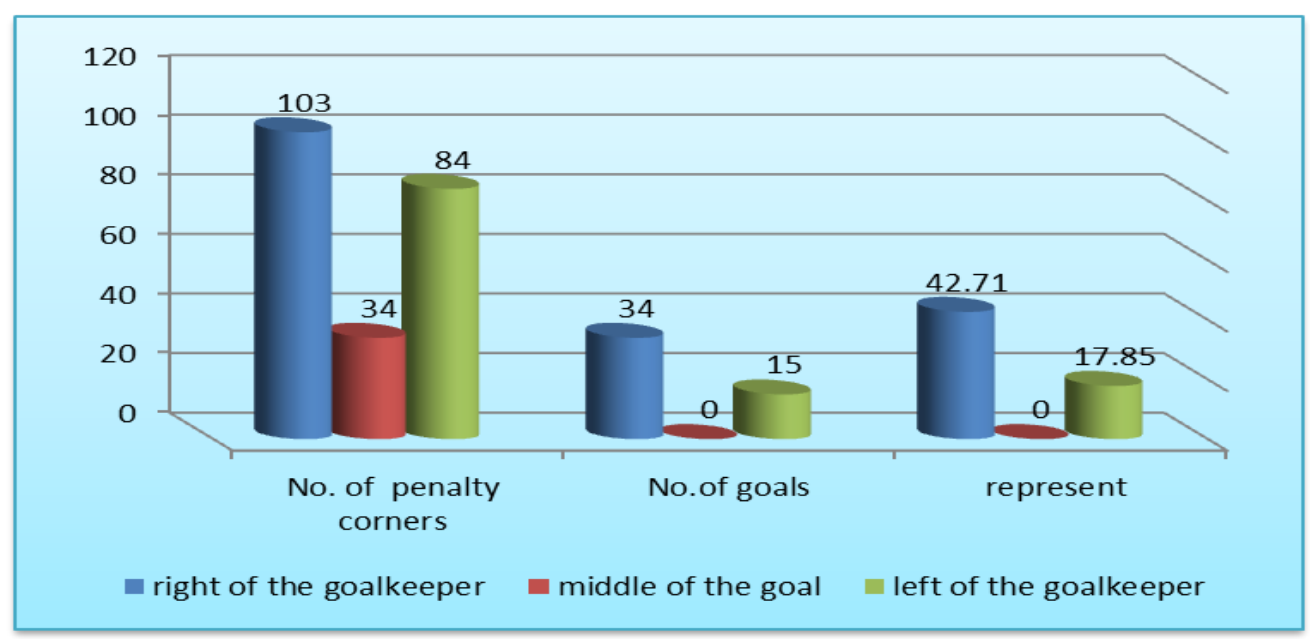

Figure (3) showed that shooting of the player none receiving the ball using drag flick skill for research sample teams from the right of the goalkeeper is more widely and effectively used than the middle of the goal and the left of the goalkeeper, that repeated (103) times out of (272) penalty corners and scored (44) goals which represent $(42.71 \%)$.

Researcher explained that this skill characterized by its strength and height from the ground and thus it is difficult for defenders to obstruct it. Drag flick is modification for flick skill with increase the speed of the ball. Also players prefer drag flick than hit skill because the role of hokey prevents the height of the ball to be more than $46 \mathrm{~cm}$ when the hit skill is the first shoot in penalty corner. 
Yusoff et al (2008), De Subijana et al (2010) stated that there is no limitation regarding the maximum ball height when the first shoot to score a goal is a push or a drag-flick during penalty corner.(34:36)(6:72)

Results of our study agree with the study of Don Vinson et al (2013) who analyzed (319) penalty corner indoor hockey, the results showed that most of penalty corner (188) representing $(58.09 \%)$ has been scored right of the goalkeeper, while (131) $(41.1 \%)$ has been scored on the left of the goalkeeper (7:890).

-Passing the ball in the circle and shooting (Right of court- middle of goalleft of court).

Figure (4): Passing the ball in the circle and shooting the goal during penalty corner

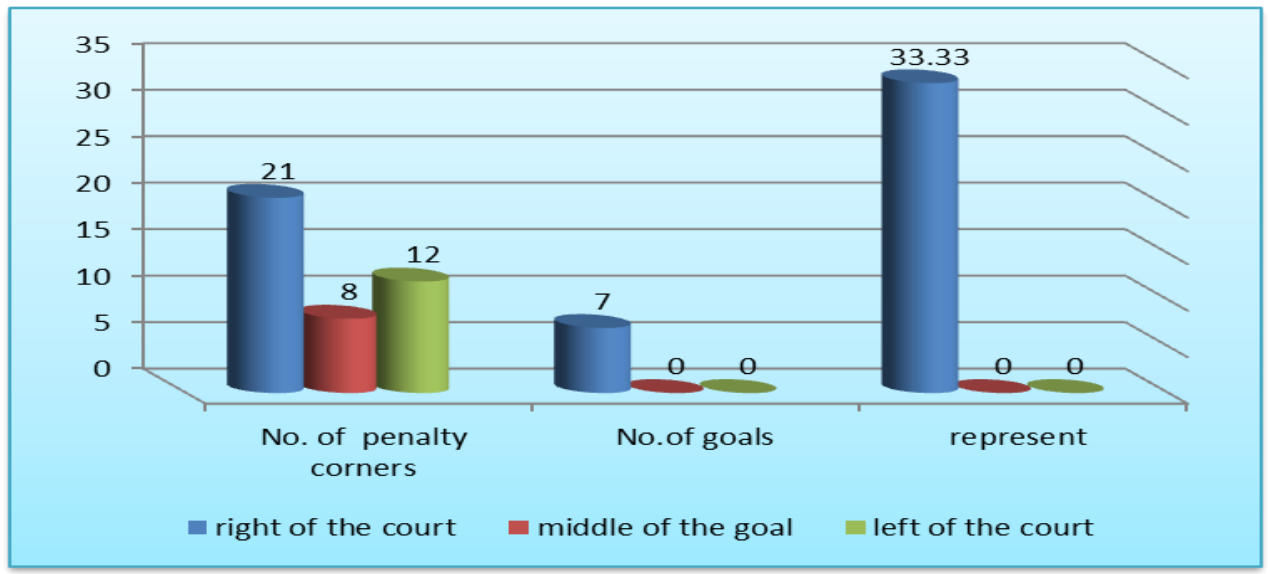

Figure (4) showed that Passing the ball in the circle after its fixation and shooting at goal in the right of court is more widely and actually used from the middle of the goal and the left of court, as it reiterated (21) times scoring (7) goals representing (33.33\%), these results agreed with Sunderland et al (2006) who confirmed that most of the attacks as well as the goals that was scored was from the right side more than the left side.(29)

Figure (5) revealed total number of penalty corners and goals scored during shooting of the player none receiving the ball using drag flick and Passing the ball in the circle.

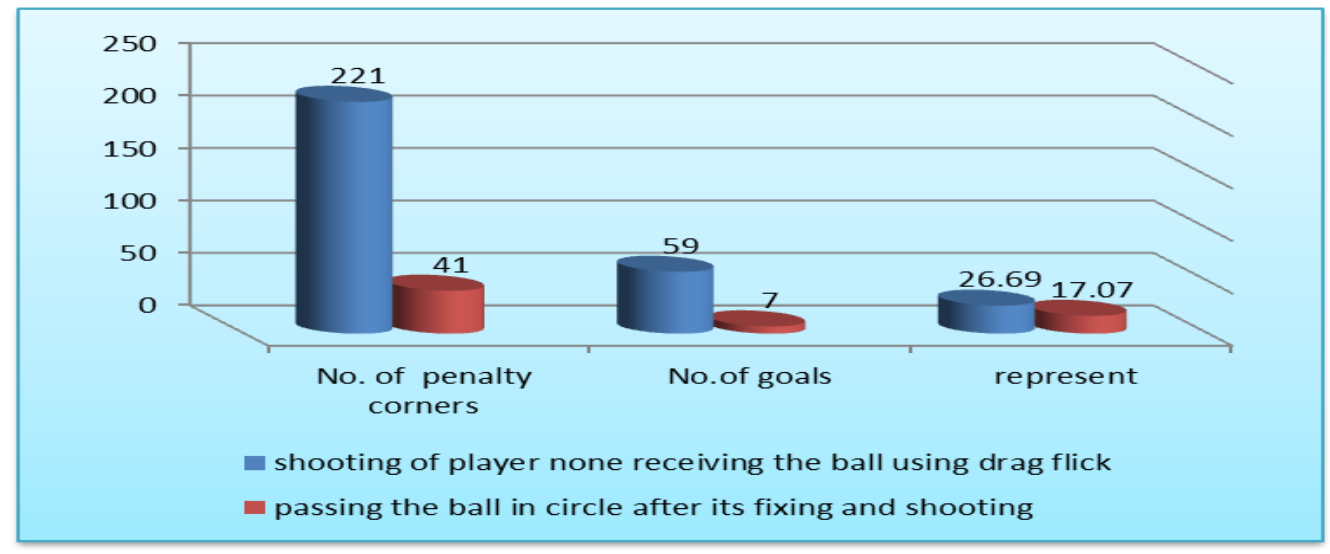


Figure (5) showed that direct shooting by player none receiving the ball using drag flick skill come at the first level as it repeated (221) times, number of goals (59), representing (26.59\%).Also it considered more effective than passing the ball in circle after its fixing and shooting at goal.

Don Vinson et al (2013) confirmed according to results of Mosquera, et al (2007)(22) that the majority of men players in field hockey shooting at goal directly using drag flick skill during penalty corner, while women shooting the ball using hit skill or ball deflection near the goal.(7:887)

\section{Conclusions and Recommendations:}

\section{Conclusions:}

Within the limits of the study's objective and results researcher reached the following conclusions:

1- Passing ball by drag is the only used skill in the first pass during ball entrance to the circle in all penalty corners.

2- Attacker's organization on the circle during penalty corner as two groups is more effective and widely used than one group for research sample teams.

3- Shooting of the player none receiving the ball using drag flick skill for research sample teams from the right of the goalkeeper is more widely and effectively used than the middle of the goal and the left of the goalkeeper.

4- Passing the ball in the circle after its fixation and shooting at goal in the right of court is more widely and actually used from the middle of the goal and the left of court.

5- Shooting of player none receiving the ball using drag flick skill is more widely and effectively used than passing the ball in the circle after its fixation and shooting at goal.

\section{Recommendations:}

1-Pay attention during education and training of players at penalty corner to the following:

- Passing ball by drag should be used in the first pass during ball entrance to the circle.

- Attackers organization on the circle during penalty corner as two groups.

- Shooting at the right of the goal keeper using drag flick by the player none receiving the ball.

- Passing the ball in the circle after its fixation, shooting at goal should be from the right of the court.

2. Appeal to the Egyptian Hockey Federation to apply and disseminate the results of this study in all areas and different ages.

3 - Conducting numerous scientific studies for the development of physical and skill requirements of attackers and defenders in penalty corner. 


\section{References:}

1- Amjad I, Hussain I, and Asadullah M. (2013).Comparison between long corners and short corners in field hockey. Rawal Medical Journal, 38, (4): 428-431.

2- Anders,E.(2008).Field hockey steps to success, Second Edition , Human Kinetics Publishers.

3- Bari,M.A ; Naushad Waheed Ansari,N.W; Ahmad,Fand Hussain, I. (2014). Three Dimensional Analysis of Drag-flick in The Field Hockey of University Players.Advances in Physics Theories and Applications, 29:87-93.

4- De Subijana, C.L; Daniel, J.D; Mallo, J and Navarro,E. (2011).The application of biomechanics to penalty corner drag-flick training: a case study. Journal of Sports Science and Medicine, 10: 590-595.

5- De Subijana, C.L; Gomez M; Martín-Casado L, Navarro E. (2012). Training-Induced changes in drag-flick technique in female field hockey players. Biol. Sport, 29:263-268.

6- De Subijana, C. L; Rez D J; Mallo J; and Navarro E. (2010). Biomechanical analysis of the penalty-corner drag-flick of elite male and female hockey players.Sports Biomechanics, 9(2): 72-78.

7- Don Vinson., Padley S., Croad A., Jeffreys M., brady A., and James D. (2013). Penalty corner routines in elite women's indoor field hockey: Prediction Of outcomes based on tactical decisions. Journal of Sports Sciences, 31, (8):887-893.

8- Hassanein,M,S and Abdel- Moneim,H. (1997). The Scientific Basis for volleyball and methods of measurement and evaluation, the book publishing center, Cairo, the second edition.

9- Hockey Rules Boord. (2004). Rules of Hockey.The International Hockey Federation.

10-Hosni, I. (1974). Study of penalty corners and its importance to the outcome of matches, Ph.D. thesis, unpublished, Faculty of Physical Education for men in Cairo, Helwan University.

11-Hussain, I. Ahmed, S. and Khan, S. (2012). Biomechanical Study on Drag Flick in Field Hockey. International journal of behavioral social and movement sciences, 1(3):186-193.

12-Kamal,A,M. (2000).Effect of some helping tools to develop the penalty corner juniors in field hockey, Master Thesis, unpublished, Faculty of Physical Education for men in Zagazig, Zagazig University. 
13-Karen, Murtaugh. (2000). Injury patterns among female field hockey players. Med. Sci. Sports Exerc, 33(2): 201- 207.

14-Kerr, R., and Ness, K. (2006). Kinematics of the field hockey penalty corner push-in. Sports Biomechanics, 5 (1):47-61.

15-Laird, P., and Sutherland, P. (2003). Penalty corners in field hockey: A guide to success. International Journal of Performance Analysis in Sport, 3 (1):19-26.

16-Lees, A. (2005). Technique analysis in sports: a critical review. Journal of Sports Sciences, 20: 813-828.

17-MacLeod, H.; Morris, J.; Nevill, A.; and Sunderland, C. (2009). The validity of a non-differential global positioning system forAssessing player movement patterns in field hockey. Journal of Sports Sciences, 127(2): 121-128.

18-Marie,M,H, and Abdel Salam ,M.(2006). analysis of differentiation biomechanical indicators between the players of higher level and less of the higher level for national Egyptian team hockey in passing ball by drag in penalty corner, Ninth International Scientific Conference of the Physical and Educational Science, Physical Education College for men , Alexandria University.

19-McLaughlin P. (1997).Three-dimensional biomechanical analysis of the hockey drag flick .Full report. National Sports Research Centre, 1 14.

20-Meulman H.N; Berger. M.; Zande M. E.; Kok, P.M.; Egbert J.C.; Ottevanger. E. J. C and Crucq M. B. (2012). Development of a tool for training the drag flick penalty corner infield hockey. 9th Conference of the International Sports Engineering Association. Netherland, 508-513.

21-Mitchell-Taverner C. (2005). Field Hockey Techniques and Tactics. Human Kinetics Publishers.

22-Mosquera, R. P., Molinuevo, J. S., and Roman, I. R. (2007). Differences between international men's and women's teams in the strategic action of the penalty corner in field hockey. International Journal of Performance Analysis in Sport, 7(3):67-83.

23-Muhammad,K,H.(2000). Effectiveness of compressor Defense (offensive) and its impact on the outcome of matches of Egyptian national handball team, unpublished Master Thesis, Faculty of Physical Education for men in Cairo, Helwan University.

24-Pineiro R., Sampedro. J and Refoyo I. (2007). Differences between international men's and women's teams in the strategic action of the penalty corner in field hockey. Int. J. Perform. Anal. Sport, 7:67-83.

25-Salama,A. (1993). Analytical study of the effectiveness of the penalty corner in field hockey, the scientific journal of Physical Education and Sports, the Conference of Research ( vision for the future of physical education sport in the Arab world ), Faculty of Physical Education for men, Helwan University, Vol. III. 
26-Sampedro J., Pineiro R.and Refoyo, I.(2008).Analisis de la accion de gol en el portero de hockey hierba. Motricidad. Eur. J. Hum. Mov, 20:75-85.

27-Sathesh, R. and Rajinikumar,P. (2014). Biomechanical Analysis of Penalty Corner Drag Flick in Field Hockey, Star Phy. Edn, 10(2):5-8.

28-Shirazi, J. (1994). Hockey umpire by taking a unified decision, hockey training course, the Egyptian Hockey Federation, Cairo.

29-Sunderland C., Bussell C., Atkinson G., Alltree R., Kates M. (2006). Patterns of play and goals scored in international standard woman's field hockey .internat J performance Analysis sport, 6:13-29.

30-Tromp, M., and Holmes, L (2011). The effect of free-hit rule Changes on match variables and patterns of play in international Standard women's field hockey. International Journal of Performance Analysis in Sport, 11(2): 376-391.

31-Viswanath,S and Kalidasan, R. (2014). Biomechanical analysis of penalty corner push-in. International journal of scientific research, 3 (6): 35-36.

32-Viswanath,S and Kalidasan, R. (2014).Correlations of Biomechanical Characteristics with Ball Speed in Penalty Corner Push-In. International Journal of Recent Research and Applied Studies, 1(1): $1-3$.

33-Ward, C. (1998). Play the Game Hockey. Planford, London.

34- Yusoff S., Hasan .N and Wilson B. (2008) Three-dimensional biomechanical analysis of the hockey drag flick performed in competition. ISN Bulletin, National Sport Institute of Malaysia, 1:3543. 